\title{
Bloco de constitucionalidade e princípios constitucionais: desafios do poder judiciário
}

\author{
Ana Maria D’Ávila Lopes ${ }^{1}$
}

Resumo: A soberania do legislador, nos moldes ideados nos séculos XVIII e XIX, tem cedido espaço à supremacia da constituição. $\mathrm{O}$ dogma da separação de poderes e a cega submissão dos juízes à lei formal têm sido substituídos pela prevalência dos direitos fundamentais, cuja força expansiva foi reconhecida na Constituição Federal de 1988, ao incorporar a teoria do bloco de constitucionalidade nas suas linhas $\left(\operatorname{art} .5^{\circ}, \S 2^{\circ}\right.$ ). No entanto, essa inovação tem intensificado ainda mais os debates sobre a legitimidade dos juízes para a concretização de normas constitucionais abertas. Nesse contexto, o presente artigo objetiva discutir como os juízes vêm enfrentado o desafio de concretizar os princípios constitucionais não previstos no texto codificado da Constituição, mas que, pela teoria do bloco, têm nível constitucional. Com essa finalidade, inicialmente será apresentada a teoria do bloco de constitucionalidade na França e na Espanha, onde teve sua origem, para, seguidamente, evidenciar a existência de um bloco de constitucionalidade no direito brasileiro. Posteriormente, o papel dos juízes na concretização dos princípios constitucionais será discutida. Finalmente, será analisada a principal jurisprudência do Supremo Tribunal sobre a temática.

Palavras-chave: Bloco de constitucionalidade. Princípios constitucionais. Poder judiciário. Supremo Tribunal Federal.
Abstract: The Parliament sovereignty, in its $18^{\text {th }}$ and $19^{\text {th }}$ century model, has been substituted by the constitution supremacy. The dogma of separation of powers and the blind submission of judges to the written law has been replaced by the prevalence of fundamental rights, the expansive strength of which has been recognized by the Federal Constitution of 1988 , by incorporating the constitutional block theory in its text $\left(\operatorname{art.} 5^{\circ}, \S 2^{\circ}\right)$. That innovation has intensified the discussion about Judiciary legitimacy to concretize constitutional principles. In that context, this paper aims to discuss how judges are facing the challenge of applying constitutional principles, which are out of the constitution, but that have constitutional hierarchy, because of the constitutional block theory. With that purpose, initially, it will be presented the constitutional block theory in France and Spain, looking to demonstrate the existence of a constitutional block in Brazilian law system. After that, it will be discussed the role of the judges to concretize constitutional principles. Finally, it will be analyzed some important jurisprudence of the Federal Supreme Court about those subjects had been analyzed.

Keywords: Constitutional block. Constitutional principles. Judiciary. Federal supreme court.

1 Mestre e doutora em Direito Constitucional pela Universidade Federal de Minas Gerais - UFMG. Professora do Programa de Pós-graduação em Direito da Universidade de Fortaleza - UNIFOR. Membro Efetivo da Câmara de Assessoramento e Avaliação Área Ciências Sociais - da FUNCAP. Bolsista de Produtividade em Pesquisa do CNPq. 


\section{Introdução}

$\mathrm{Na}$ atualidade, os juízes enfrentam com maior frequência o desafio de interpretar normas constitucionais abstratas, vagas e ambíguas. A presença desse tipo de normas, na maioria das constituições modernas, tem se tornado uma das mais relevantes preocupações da Teoria Constitucional, na medida em que exige do juiz o exercício de uma tarefa que vai além dos contornos definidos pela tradicional hermenêutica jurídica.

Essa situação tem deflagrado a necessidade de justificar política e moralmente a jurisdição constitucional (ALEXY, 1988), especialmente diante da denominada "objeção democrática", que coloca em dúvida a legitimidade do juiz para concretizar princípios constitucionais em razão de alguns, implicar na imposição de valores subjetivos ao resto da população (IGLESIAS, 2003, p. 253).

A questão foi delineada, com precisão, por Luís Roberto Barroso:

[...] tem-se travado, nos últimos anos, uma ampla discussão sobre o controle de constitucionalidade pelo Judiciário e seus limites. Sustenta-se que os agentes do Poder Executivo e do Legislativo, além de ungidos pela vontade popular, sujeitam-se a um tipo de controle e responsabilização política de que os juízes estão isentos. Daí afirmar-se que o controle judicial da atuação dos outros Poderes dá lugar ao que se denominou de 'countermajoritarian difficulty' (dificuldade contramajoritária). Notadamente os segmentos conservadores têm questionado o avanço dos tribunais sobre espaços que, segundo crêem, deveriam ficar reservados ao processo político. (BARROSO, 2003, p. 168).

A controvérsia tem se acirrado ainda mais no Estado brasileiro com a adoção do bloco de constitucionalidade, nos termos do $\S 2^{\circ}$ do art. $5^{\circ}$ da Constituição Federal de 1988, haja vista os juízes terem agora que concretizar não apenas os princípios constitucionais previstos expressamente no texto constitucional, mas fora dele (LOPES; MARQUES, 2007). 
Nesse contexto, é que, no presente trabalho, será discutido como o Supremo Tribunal Federal vem enfrentando esse desafio. Para tal, inicialmente, serão apresentadas as noções básicas sobre o bloco de constitucionalidade no direito francês e espanhol, onde teve sua origem, sendo também evidenciada a sua existência no sistema jurídico brasileiro. Seguidamente, as controvérsias sobre o papel do juiz constitucional perante os princípios constitucionais será discutida. Finalmente, será analisado o bloco de constitucionalidade brasileiro como parâmetro da constitucionalidade das normas, a partir do estudo da jurisprudência do Supremo Tribunal Federal.

\section{O bloco de constitucionalidade no direito comparado e brasileiro}

A expressão bloc de constitucionalité originou-se na doutrina administrativista francesa, capitaneada por Maurice Hauriou, a partir da criação de um "bloco de legalidade" com base nas atividades desenvolvidas pelo Conselho do Estado, órgão encarregado de exercer o controle dos atos administrativos na França. A existência de um conjunto de normas, em um sistema jurídico, formando um todo de igual nível hierárquico, foi posteriormente incorporada ao direito constitucional (FAVOREU; RUBIO LLORENTE, 1990, p. 20).

Segundo Favoreu (1990, p. 20), a ideia de "bloco" remonta a um conjunto de coisas consideradas como uma unidade, sólida e unificada, que não pode ser cindida nem dividida. Nesse sentido, o bloco de constitucionalidade pode ser definido como "o conjunto de normas que, junto com a constituição codificada de um Estado, formam um bloco normativo de nível constitucional” (LOPES; MORAES, 2008b, p. 25).

O bloco de constitucionalidade francês foi definido no início dos anos 1970, quando, em decisão de 16 de julho de 1971, o Conseil Constitutionnel elevou a liberdade de associação ao patamar de "princípio fundamental reconhecido pelas leis da República". Nessa sentença, o Conselho Constitucional firmou a existência, no sistema jurídico francês, de um bloco de princípios e regras dotadas de nível constitucional, 
composto pela Constituição de 1958, o Preâmbulo da Constituição de 1946, a Declaração dos Direitos do Homem e do Cidadão de 1789 e os princípios fundamentais reconhecidos pelas leis da República.

Apesar da decisão de 1971 ter configurado expressamente as normas que iriam compor o bloc de constitucionalité, constata-se que o Conseil Constitutionnel, no início de suas atividades, aplicou com grande liberdade essas normas, devido à falta de precisão sobre seu conteúdo.

A possibilidade de estender o conteúdo do bloco de constitucionalidade, de forma praticamente ilimitada, deflagrou a necessidade de uma construção teórica capaz de delimitar e consolidar o rol dos direitos que deveriam ser compreendidos sob esse conceito, evitando-se, desse modo, cair no risco do ativismo do juiz constitucional (FAVOREU; RUBIO LLORENTE, 1990, p. 41).

A resolução desse problema, aventado por Favoreu, veio com a renovação parcial do Conseil Constitutionnel na década de 1980, sobretudo na figura de Georges Vedel, que afirmou que o juiz constitucional deveria apoiar-se somente nas disposições contidas expressamente nos citados textos constitucionais, e não em conceitos vagos. Assim, destaca Favoreu:

Se puede comprobar, efectivamente, estudiando la jurisprudencia que, a partir de 1980, hay una restricción de las categorías de normas de referencia. Así, en 1989, "el bloque de la constitucionalidad stricto sensu se compone exclusivamente de textos de nivel constitucional, a saber, la propia Constitución de 1958, la Declaración, el Preámbulo y las "leyes de la República", en la medida en que sean portadoras de "principios fundamentales. (FAVOREU; RUBIO LLORENTE, 1990, p. 24).

A partir desse momento, a concepção francesa de bloco de constitucionalidade tornou-se mais estável, na medida em que a jurisprudência do Conseil Constitutionnel evoluiu ao conduzir o conteúdo do bloco a uma categoria normativa definida, ou ao menos, a um conjunto de regras identificáveis. 
O juiz Constitucional francês, explica Favoreu, chegou, em menos de vinte anos, a realizar o que cerca de dois séculos de história não haviam conseguido levar a cabo: a definição de um conjunto de normas que combinavam a modernidade com as tradições, ao qual os direitos fundamentais foram finalmente integrados (FAVOREU; RUBIO LLORENTE, 1990, p. 41).

O Conseil Constitutionnel conseguiu, assim, por meio de uma conduta audaciosa, alargar o âmbito das suas funções, assumindo um papel que veio a se revelar fundamental para a França (SEGORBE, online).

$\mathrm{Na}$ Espanha, por outro lado, a noção de bloque de constitucionalidad começou a tomar formato somente nos anos 1980, com a atuação do Tribunal Constitucional, que consagrou, pela primeira vez, esta expressão na STC 10/1982.

No entanto, ainda hoje, o Tribunal Constitucional espanhol não tem conseguido definir de modo preciso o conteúdo do seu bloque de constitucionalidad. Segundo Rubio Llorente, membro dessa Corte, isso ocorre porque o bloco de constitucionalidade é entendido, algumas vezes, como um conjunto concreto de normas aplicadas ao caso concreto, enquanto, em outras ocasiões, o bloco é considerado o elenco de todas as normas que prevalecem sobre o restante das leis das Comunidades Autônomas (FAVOREU; RUBIO LLORENTE, 1990, p. 97).

Assim, diferentemente do que ocorre com o bloco de constitucionalidade francês, o espanhol apresenta-se indeterminado. São dois os motivos que provocam essa situação: a) a complexidade da repartição de competências entre o Estado central espanhol e as Comunidades Autônomas; e b) o extenso rol de direitos fundamentais contido no texto formal da Constituição espanhola, a exemplo da Constituição brasileira de 1988.

No direito espanhol, o bloco é basicamente formado por um conjunto de preceitos que não pertencem formalmente à Constituição, mas que apresentam teor de norma material constitucional e que, por isso, o Tribunal Constitucional os vincula à Carta Espanhola, formando, 
com esta, um bloco do qual não pode ser dissociado. Importante exemplo desse tipo de norma são os Estatutos das Comunidades Autônomas.

Apesar de o conteúdo do bloco de constitucionalidade espanhol divergir do francês, ressalta-se que, nas duas experiências, as normas que o compõem servem como parâmetros para o controle de constitucionalidade.

No Brasil, a defesa da existência de um bloco de constitucionalidade está ancorada no $\S 2^{\circ}$ do art. $5^{\circ}$ da Constituição Federal de 1988 , no qual se estabelece que os direitos e garantias expressos na Lei Fundamental não excluem outros decorrentes dos princípios ou do regime por ela adotados, assim como os previstos em tratados internacionais sobre direitos humanos dos quais o Brasil faça parte.

Essa norma evidencia o reconhecimento da forca expansiva da dignidade humana e dos direitos fundamentais no sistema jurídico pátrio (PIOVESAN, 1995, p. 160). Deve-se, desse modo, entender que os direitos e as garantias fundamentais não são apenas os que se encontram expressos na Constituição, mas também aqueles que possam hermeneuticamente decorrer do regime democrático adotado e dos princípios constitucionais previstos, além dos que se encontrem em documentos internacionais, desde que versem sobre direitos humanos.

Cita-se, como exemplo desse entendimento, decisão proferida pelo Supremo Tribunal Federal no RE n. 248.869/SP, ${ }^{2}$ a respeito da

2 "RECURSO EXTRAORDINÁRIO. CONSTITUCIONAL. PROCESSUAL CIVIL. LEGITIMIDADE ATIVA DO MINISTÉRIO PÚBLICO PARA AJUIZAR AÇÃO DE INVESTIGAÇÃO DE PATERNIDADE. FILIAÇÃO. DIREITO INDISPONÍVEL. INEXISTÊNCIA DE DEFENSORIA PÚBLICA NO ESTADO DE SÃO PAULO. 1. A Constituição Federal adota a família como base da sociedade a ela conferindo proteção do Estado. Assegurar à criança o direito à dignidade, ao respeito e à convivência familiar pressupõe reconhecer seu legítimo direito de saber a verdade sobre sua paternidade, decorrência lógica do direito à filiação (CF, artigos 226 , §§ 3o, 4o, 5o e 7o; 227, § 6o). 2. A Carta Federal outorgou ao Ministério Público a incumbência de promover a defesa dos interesses individuais indisponíveis, podendo, para tanto, exercer outras atribuições prescritas em lei, desde que compatível com sua finalidade institucional (CF, artigos 127 e 129). 3. O direito ao nome insere-se no conceito de dignidade da pessoa humana e traduz a sua identidade, a origem de sua ancestralidade, o reconhecimento da família, razão pela qual o estado de filiação é direito indisponível, em função do bem comum maior a proteger, derivado da própria força impositiva dos preceitos de ordem pública que regulam a matéria 
legitimidade do Ministério Público para propor ação de investigação de paternidade. Na decisão houve o reconhecimento de um direito fundamental à filiação e ao nome, ambos não previstos expressamente na Constituição Federal de 1988, mas considerados assim pela sua fundamentalidade.

A ampliação do rol dos direitos fundamentais para além do próprio texto codificado, com base na abrangência material da Constituição de 1988, vem a confirmar não apenas a existência de um bloco de constitucionalidade brasileiro, mas, e especialmente, a relevância da função interpretadora do Supremo Tribunal Federal na consolidação da democracia e na defesa dos direitos fundamentais.

\section{O controle jurisdicional de constitucionalidade e as consti- tuições principiológicas}

A fundamentação jurídica do controle de constitucionalidade das leis reside no próprio conceito de constituição, entendida como norma suprema decorrente da soberana vontade do povo e, como tal, colocada no nível hierárquico superior do sistema jurídico. A constituição, como base e fundamento da estrutura normativa, determina os valores supremos do ordenamento jurídico e constitui o parâmetro de validade de todas as demais normas. Nesse sentido, o estabelecimento de mecanismos de proteção da integridade do texto constitucional respondem à necessidade de proteger a ordem fundamental, diante de possíveis violações pelo ordenamento jurídico ordinário.

(Estatuto da Criança e do Adolescente, artigo 27). 4. A Lei n. 8.560/92 expressamente assegurou ao Parquet, desde que provocado pelo interessado e diante de evidências positivas, a possibilidade de intentar a ação de investigação de paternidade, legitimação essa decorrente da proteção constitucional conferida à família e à criança, bem como da indisponibilidade legalmente atribuída ao reconhecimento do estado de filiação. Dele decorrem direitos da personalidade e de caráter patrimonial que determinam e justificam a necessária atuação do Ministério Público para assegurar a sua efetividade, sempre em defesa da criança, na hipótese de não reconhecimento voluntário da paternidade ou recusa do suposto pai. [...]. Recurso extraordinário conhecido e provido" (STF 2003, on-line). 
Com essa finalidade, nos inícios do século XX, a consolidação do Estado de Direito na Europa continental demandou a criação de um sistema de controle de constitucionalidade capaz de preservar a Lei Maior do Estado, mas sem ferir a independência do Parlamento.

Nesse contexto, Kelsen ideou a criação de um órgão especial, um tribunal constitucional, no intuito de conciliar a defesa da constituição e a liberdade política do Parlamento. O sistema ideado pelo mestre austríaco consistia na exclusão do conhecimento de fatos pelo tribunal constitucional, competindo-lhe apenas a função de julgar a compatibilidade lógica entre dois enunciados normativos perfeitamente cristalizados, mas carentes de qualquer referência fática. Devido precisamente a isso, é que, conforme leciona Gascón (2003, p. 167 et seq.), o sistema foi denominado "jurisdição concentrada (um único órgão, um tribunal fora da estrutura do Judiciário) e abstrata" (não relativa a fatos concretos).

O sistema de Kelsen (1994) guardava coerência com sua concepção de constituição, considerada principalmente uma norma de organização e de procedimento de criação de outras normas que, embora pudesse indicar o conteúdo dessas outras normas a serem criadas, nunca essa indicação poderia fundar-se em um sistema de valores e princípios. A afirmação kelseniana do caráter formal da constituição resultava essencial para garantir não apenas a possibilidade de um juízo lógico-racional sobre a validade das normas infraconstitucionais, mas também como forma de reconhecer e respeitar a liberdade política do Parlamento na criação dessas normas.

Daí também a necessidade kelseniana de rejeitar qualquer tipo de expressão vaga ou ambígua nos enunciados normativos constitucionais, que pudesse comprometer a imparcialidade e exatidão lógica do juiz constitucional no exercício do controle normativo.

Expressões como "justiça", "igualdade", "liberdade", etc. não deveriam estar presentes no texto constitucional (KELSEN, 1988, p. 143), pois não seria admissível que um tribunal constitucional anulasse, por exemplo, uma lei invocando apenas o fato de ser uma "lei injusta", na medida em que o conceito de justiça de um juiz constitucional poderia não coincidir com o conceito de justiça da maioria da população, e visto que, anulando essa lei, o tribunal constitucional estaria anulando a 
decisão da maioria do Parlamento que aprovou essa lei considerada por eles como justa. Segundo KELSEN (1988, p. 143), "la constitución debe, especialmente si crea un Tribunal constitucional, abstenerse de todo este tipo de fraselogía y, si quiere establecer principios relativos al contenido de las leyes, formularlas del modo más preciso posible".

O objetivo do sistema kelseniano, nas palavras magistrais de Gascón, era:

[...] en primer lugar, verificar un juicio abstracto de normas donde quedase excluida toda ponderación de los valores e intereses que subyacen a la ley o a los hechos que son objeto de su aplicación, por cuanto tales valores e intereses son la fuente y vehículo de la subjetividad e ideología; $y$, en, segundo término, adoptar como exclusivo parámetro de enjuiciamiento una constitución concebida como regla procedimental y de organización, y no como generadora de problemas morales y substantivos. (GASCON, 2003, p. 168).

$\mathrm{Na}$ atualidade, o modelo de controle de constitucionalidade de Kelsen não é aplicado na sua forma pura em nenhum lugar do mundo. O principal motivo talvez se deva ao fato de que muitas das atuais constituições não correspondem ao modelo de constituição formal - organizativa e procedimental - ideado pelo mestre austríaco, mas apresentam no seu texto diversas normas principiológicas, com conteúdos abertos, vagos e imprecisos. Assim, a Constituição brasileira de 1988 oferece um claro exemplo dessa nova tendência, visto ser um texto composto de diversas normas-princípio (cidadania, art. $1^{\circ}$, II; dignidade humana, art. 1ㅇ, III; sociedade livre, justa e solidária, art. $3^{\circ}$, I; etc.), afastando-se do formalismo lógico normativo kelseniano.

A presença desse tipo de normas-princípio nas constituições tem sido matéria de diversas teorias, que vêm ganhando espaço cada vez mais no âmbito da Teoria do Direito e, em especial, da Teoria Constitucional. Nesse sentido, teóricos como Dworkin e Alexy têm afirmado a distinção entre princípios e regras, definindo os primeiros como simples razões para decidir que "deben tenerse en cuenta" (DWORKIN, 1984, p. 77-78), enquanto as segundas "exigen un cumplimiento pleno $y$, en esa medida, pueden ser sólo cumplidas o incumplidas" (ALEXY, 1993, p. 81 et seq.). 
Os princípios para o mestre alemão são normas que "ordenan que se realice algo en la mayor medida posible [...] son mandatos de optimización" (ALEXY, 1993, p. 81).

A abstração dos princípios impede determinar com precisão em que casos sua aplicação é procedente. Tal circunstância abre a possibilidade de que em um único caso vários princípios possam ser simultaneamente aplicados, exigindo, do juiz constitucional, sua otimização em um juízo de ponderação ou razoabilidade.

O tradicional ideal da unidade da solução correta para cada caso é hoje dificilmente mantido no âmbito da jurisdição constitucional. Os juízes constitucionais muitas vezes têm enfrentado situações que demandam uma aproximação diferente daquela utilizada anteriormente, ou, pior ainda, evitando entrar em conflito com a liberdade política do Parlamento, os tribunais têm-se abstido de se pronunciar em muitos casos (LOPES, 2008a).

Contudo, essa situação não deve ser interpretada como a volta à velha concepção da falta da força vinculante de algumas normas da constituição (GASCON, 2003, p. 185), pois os juízes constitucionais têm feito uso frequente de todas as normas, inclusive dos princípios fundamentais. O que deve concluir-se é apenas que os princípios constitucionais não oferecem uma única solução em cada conflito, exigindo um maior e melhor trabalho interpretativo do juiz constitucional na fundamentação de sua decisão.

Segundo Gascón (2003, p. 185), os tribunais constitucionais estariam afastando-se do modelo lógico-formal kelseniano de jurisdição constitucional concentrada, para se aproximarem do modelo interpretativo norte-americano de jurisdição difusa, na medida em que os princípios constitucionais reclamam do juiz constitucional o desenvolvimento de uma argumentação racional que fundamente sua decisão. A tradicional concepção do juiz como apenas um agente que realiza uma função lógica formal de subsunção de normas deve ser considerada superada.

No entanto, esse novo papel dos juízes, na concretização dos princípios constitucionais, tem levantado a questão de que o Judiciário teria abandonado o sistema lógico-formal kelseniano, para cair no 
subjetivismo, como décadas antes o alertava Schmitt. Na verdade, ambas as posições radicais devem ser consideradas superadas. A posição dos juízes deve estar a meio caminho entre a mais ingênua escola exegética e o ilegítimo subjetivismo.

\section{O bloco de constitucionalidade como parâmetro para o controle de constitucionalidade}

No Brasil, o debate sobre o papel do juiz constitucional tem se acirrado ainda mais a partir da promulgação da Constituição Federal de 1988, devido a não apenas ter agora que concretizar o conteúdo das normas-princípio presentes no seu texto, mas, por força da adoção do bloco de constitucionalidade (art. $5^{\circ}, \S 2^{\circ}$ ), poder invocar normas fora da própria Lei Maior.

Nesse sentido, a inconstitucionalidade de uma lei ou ato pode agora, por exemplo, ser determinada não apenas a partir da sua inadequação à Constituição codificada, mas também ao conjunto de normas materialmente constitucionais (LIMA, 2004, p. 104):

A definição do significado de bloco de constitucionalidade - independentemente da abrangência material que se lhe reconheça - revestese de fundamental importância no processo de fiscalização normativa abstrata, pois a exata qualificação conceitual dessa categoria jurídica projeta-se como fator determinante do caráter constitucional, ou não, dos atos estatais contestados em face da Carta Política.

Canotilho, a respeito deste ponto, posiciona-se brilhantemente ao afirmar que:

Todos os atos normativos devem estar em conformidade com a Constituição. Significa isto que os atos legislativos e restantes atos normativos devem estar subordinados, formal, procedimental e substancialmente, ao parâmetro constitucional. Mas qual é o escalão normativo de acordo com o qual se deve controlar a conformidade dos atos normativos? As respostas a este problema oscilam fundamentalmente entre duas posições: 1) o parâmetro constitucional equivale 
à constituição escrita ou leis com valor constitucional formal, e daí que a conformidade dos atos normativos só possa ser aferida, sob o ponto de vista da sua constitucionalidade ou inconstitucionalidade, segundo as normas e princípios escritos da constituição (ou de outras leis formalmente constitucionais); 2) o parâmetro constitucional é a ordem constitucional global, e, por isso, o juízo de legitimidade constitucional dos atos normativos deve fazer-se não apenas segundo as normas e princípios escritos nas leis constitucionais, mas também tendo em conta princípios não escritos integrantes da ordem constitucional global. (CANOTILHO, 1999, p. 811-812).

Com a expressa previsão de um bloco de constitucionalidade na Constituição Federal de 1988 (art. 5 $5^{\circ} 2^{\circ}$ ), o Supremo Tribunal Federal - STF, enquanto guardião da Constituição (art. 102, caput), tem embasamento legal para adotar o segundo posicionamento assinalado por Canotilho, ou seja, a Corte brasileira pode invocar normas materialmente constitucionais como parâmetros de constitucionalidade.

No entanto, o próprio STF vem assumindo uma posição bastante cautelosa a respeito, conforme o expressado no julgamento da ADin 595/ ES (fev. 2002):

EMENTA: AÇÃO DIRETA DE INCONSTITUCIONALIDADE. INSTRUMENTO DE AFIRMAÇÃO DA SUPREMACIA DA ORDEM CONSTITUCIONAL. O PAPEL DO SUPREMO TRIBUNAL FEDERAL COMO LEGISLADOR NEGATIVO. A NOÇÃO DE CONSTITUCIONALIDADE / INCONSTITUCIONALIDADE COMO CONCEITO DE RELAÇÃO. A QUESTÃO PERTINENTE AO BLOCO DE CONSTITUCIONALIDADE. POSIÇÕES DOUTRINÁRIAS DIVERGENTES EM TORNO DO SEU CONTEÚDO. O SIGNIFICADO DO BLOCO DE CONSTITUCIONALIDADE COMO FATOR DETERMINANTE DO CARÁTER CONSTITUCIONAL, OU NÃO, DOS ATOS ESTATAIS. NECESSIDADE DA VIGÊNCIA ATUAL, EM SEDE DE CONTROLE ABSTRATO, DO PARADIGMA CONSTITUCIONAL ALEGADAMENTE VIOLADO. SUPERVENIENTE MODIFICAÇÃO/ SUPRESSÃO DO PARÂMETRO DE CONFRONTO. PREJUDICIALIDADE DA AÇÃO DIRETA. 
[...] O controle concentrado de constitucionalidade, por isso mesmo, transforma, o Supremo Tribunal Federal, em verdadeiro legislador negativo (RTJ 126/48, Rel. Min. MOREIRA ALVES RTJ 153/765, Rel. Min. CELSO DE MELLO - ADI 1.063-DF, Rel. Min. CELSO DE MELLO). É que a decisão emanada desta Corte - ao declarar, in abstrato, a ilegitimidade constitucional de lei ou ato normativo federal ou estadual - importa em eliminação dos atos estatais eivados de inconstitucionalidade (STF 2002, on-line).

Esse posicionamento vem sendo mantido, conforme pode ser constatado em decisões mais recentes, como na ADI 514/PI de março de 2008, na qual o STF determinou que seja o autor da ação quem expressamente assinale as normas pertencentes ao bloco que invoca como parâmetros da inconstitucionalidade da lei ou ato questionado:

EMENTA: FISCALIZAÇÃO NORMATIVA ABSTRATA. REVOGAÇÃO TÁCITA DE UMA DAS NORMAS LEGAIS IMPUGNADAS E MODIFICAÇÃO SUBSTANCIAL DO PARÂMETRO DE CONTROLE INVOCADO EM RELAÇÃO AOS DEMAIS DIPLOMAS LEGISLATIVOS QUESTIONADOS. HIPÓTESES DE PREJUDICIALIDADE DA AÇÃO DIRETA, QUANDO SUPERVENIENTES AO SEU AJUIZAMENTO. A NOÇÃODECONSTITUCIONALIDADE/INCONSTITUCIONALIDADE COMO CONCEITO DE RELAÇÃO. A QUESTÃO PERTINENTE AO BLOCO DE CONSTITUCIONALIDADE. POSIÇÕES DOUTRINÁRIAS DIVERGENTES EM TORNO DO SEU CONTEÚDO. O SIGNIFICADO DO BLOCO DE CONSTITUCIONALIDADE COMO FATOR DETERMINANTE DO CARÁTER CONSTITUCIONAL, OU NÃO, DOS ATOS ESTATAIS. IMPUGNAÇÃO GENÉRICA DEDUZIDA EM SEDE DE CONTROLE ABSTRATO. INADMISSIBILIDADE. DEVER PROCESSUAL, QUE INCUMBE AO AUTOR DA AÇÃO DIRETA, DE FUNDAMENTAR, ADEQUADAMENTE, A PRETENSÃO DE INCONSTITUCIONALIDADE. SITUAÇÃO QUE LEGITIMA O NÃO CONHECIMENTO DA AÇÃO DIRETA. PRECEDENTES.

[...] Impõe-se, ao autor, no processo de controle concentrado de constitucionalidade, indicar as normas de referência - que são aquelas inerentes ao ordenamento constitucional e que se 
revestem, por isso mesmo, de parametricidade - em ordem a viabilizar, com apoio em argumentação consistente, a aferição da conformidade vertical dos atos normativos de menor hierarquia. Quaisquer que possam ser os parâmetros de controle que se adotem - a Constituição escrita ou a ordem constitucional global (J. J. GOMES CANOTILHO, "Direito Constitucional", p. 712, 4a ed., 1987, Almedina, Coimbra) -, não pode o autor deixar de referir, para os efeitos mencionados quais as normas, quais os princípios e quais os valores efetiva ou potencialmente lesados por atos estatais revestidos de menor grau de positividade jurídica, sempre indicando, ainda, os fundamentos, a serem desenvolvidamente expostos subjacentes à argüição de inconstitucionalidade [...] (STF 2008, on-line).

As reticências existentes no Direito pátrio para aceitar a existência de um bloco de constitucionalidade têm suas raízes na adoção do legalismo, que reduz a Constituição a uma lei técnica de organização do poder e exteriorização formal de direitos. O intérprete desta Constituição é conservador por excelência, aplicando o Direito por meio de uma operação lógica (ato de subsunção), e não ato criador ou sequer aperfeiçoador (LIMA, 2004, p. 171).

Essa reduzida visão do papel do juiz deriva da noção de democracia como sinônimo de maioria corporificada no Legislativo, sendo invocada para questionar a legitimidade do Judiciário (VIDAL, 2008), cujos membros não foram eleitos pelo povo.

À evidência, é inexorável que ocorra um certo tensionamento entre os Poderes do Estado a partir da seguinte equação: de um lado, um texto constitucional fruto de um pacto constituinte forjado na tradição do segundo pós-guerra estipulando e apontando a necessidade da realização dos direitos fundamentais; e de outro, a difícil convivência entre os Poderes do Estado, eleitos (Executivo e Legislativo) por maiorias nem sempre concordantes com os ditames constitucionais. Ao lado dessa problemática, há a questão da legitimidade de o Poder Judiciário (justiça constitucional) desconstituir atos normativos do Poder Executivo ou declarar a inconstitucionalidade de leis votadas pelo parlamento eleito democraticamente pelo povo (STRECK, 2004, p. 110). 
Não obstante, a democracia não pode hoje ser definida como sinônimo de maioria e menos como sinônimo de verdade.

Democracia significa governo submetido a condições - nós podemos chamá-las de 'condições democráticas' - de igual status para todos os cidadãos. Quando instituições majoritárias provêem e respeitam as condições democráticas, então as decisões dessas instituições devem ser aceitas por todos por aquela razão. Mas quando não o fazem, ou quando seu provimento ou respeito é deficiente, não se pode fazer objeção, em nome da democracia, contra outros procedimentos que protejam ou respeitem melhor aquelas condições. (DWORKIN, 1996, p. 17).

Por outro lado, o reconhecimento do papel do STF como verdadeiro guardião da Constituição não necessariamente significa atribuir-lhe a função de legislador positivo, mas de intérprete supremo da norma constitucional. O STF, na defesa dos direitos e garantias fundamentais, não necessariamente estará criando norma constitucional ao invocar norma não contemplada expressamente no texto da nossa Lex Fundamentalis, mas poderá estar apenas interpretando o bloco de constitucionalidade e assim deverá ser entendido, sob pena de engessar o ordenamento constitucional brasileiro e relegar a proteção da dignidade humana a um segundo plano.

\section{Conclusão}

A fundamentação jurídica do controle de constitucionalidade das leis reside no próprio conceito de constituição entendida como norma suprema decorrente da soberana vontade do povo e, como tal, colocada no nível hierárquico superior do sistema jurídico. A constituição, como base e fundamento da estrutura normativa, determina os valores supremos do ordenamento jurídico e constitui o parâmetro de validade de todas as demais normas. Nesse sentido, o estabelecimento de mecanismos de proteção da integridade do texto constitucional respondem à necessidade de proteger a ordem fundamental diante de possíveis violações pelo ordenamento jurídico ordinário. 
No entanto, a adoção de princípios constitucionais e do bloco de constitucionalidade em alguns sistemas jurídicos, como o brasileiro, vêm levantando a discussão sobre o papel do juiz constitucional como protetor da Lei Maior, devido aos perigos do ativismo judicial, alertados antes por Schmitt. Contudo, esse temor deve ser superado, aceitandose essa nova realidade como uma valiosa oportunidade na qual "puede fructificar la argumentación racional que sirva de base a una doctrina de la interpretación que, en opinión nada exagerada se presenta como 'el núcleo mismo de la teoría de la constitución y del derecho constitucional" (GASCON, 2003, p. 191). É, nessa linha, que o Supremo Tribunal Federal, corte constitucional brasileira, deve pautar sua atuação, cumprindo, dessa forma, a sua função de verdadeiro guardião da Constituição.

\section{Referências}

ALEXY, Robert. Teoría de los derechos fundamentales. Madri: Centro de Estudios Constitucionales, 1993.

. Sistema jurídico, principios jurídicos y razón práctica. Cuadernos de filosofia del derecho, n. 5, Madri: Doxa, p. 139-151, 1988.

BARROSO, Luís Roberto. Interpretação e aplicação da constituição: fundamentos de uma dogmática constitucional transformadora. São Paulo: Saraiva, 2003.

CANOTILHO, J. J. G. Direito constitucional e teoria da constituição. 3. ed. Coimbra: Almedina, 1999.

DWORKIN, Ronald. Freedom's Law: the moral reading of the american constitution. Cambridge: Harvard University Press, 1996.

DWORKIN, Ronald. Los derechos en serio. Barcelona: Ariel, 1984.

FAVOREU, Louis; RUBIO LLORENTE, Francisco. El bloque de la constitucionalidad: simposium franco-espanhol de derecho constitucional. Madri: Civitas, 1991. 
GASCÓN ABELLÁN, Marina. Los límites de la Justicia Constitucional. In: LAPORTA, Francisco J (ed). Constitución: problemas filosóficos. Madri: Centro de Estudios Políticos y Constitucionales, 2003.

IGLESIAS VILA, Marisa. Los conceptos esencialmente controvertidos en la interpretación constitucional. In: LAPORTA, Francisco J (ed). Constitución: problemas filosóficos. Madri: Centro de Estudios Políticos y Constitucionales, 2003.

KELSEN, Hans. Teoria pura do direito. Buenos Aires: Eudeba, 1994. . La garantia jurisdicional de la Constitución (La justicia constitucional). In: Escritos sobre la democracia y el socialismo. Madri: Debate, 1988.

LIMA, Francisco Gerson Marques de. Bloco de constitucionalidade: os sistemas francês e espanhol. Revista opinião jurídica, n. 3, ano II, Fortaleza, 2004.

LOPES, Ana Maria D’Ávila. Jurisdição constitucional e constituições principiológicas. In: SALES, Lilia Maia de Morais Sales; LIMA, Martonio Mont'Álverne Barreto (Org.) Constituição, democracia, poder judiciário e desenvolvimento. Florianópolis: Conceito Editorial, 2008a, p. 39-66.

LOPES, Ana Maria D’Ávila. MORAES, Ismael Evangelista Benevides. Direito constitucional. 2 ed. Fortaleza: LCR, 2008b.

LOPES, Ana Maria D'Ávila. MARQUES, Samuel de Araújo. O bloco de constitucionalidade o direito comparado e no direito brasileiro.

In: RODRIGUES, Francisco Luciano Lima. Estudos de direito constitucional e urbanistico. São Paulo, RCS, 2007, p. 39-54.

MENDES, Gilmar Ferreira. Controle de constitucionalidade: Hermenêutica Constitucional e revisão de fatos e prognoses legislativos pelo órgão judicial. In: Direitos fundamentais e controle de constitucionalidade. São Paulo: Celso Bastos Editor, 1998.

MAC CORMICK, Neil. Legal reasoning and legal theory. Oxford: Clarendon Press, 1978. 
OTTO, Ignacio de. La posición del Tribunal Constitucional a partir de la doctrina de la interpretación constitucional. In: El Tribunal Constitucional, vol. I. Madri: IEF, 1981.

PIOVESAN, Flávia. Direitos humanos e o direito constitucional internacional. São Paulo: Revista dos Tribunais, 1995.

SEGORBE, Beatriz. O Conselho Constitucional francês e a proteção dos direitos fundamentais. Disponível em: http:/www.fd.unl.pt/web/Anexos/ Downloads/215.pdf. Acesso em: 14 dez. 2006.

STRECK, Lenio Luiz. Jurisdição constitucional e hermenêutica: uma nova crítica do direito. Rio de Janeiro: Forense, 2004.

SUPREMO TRIBUNAL FEDERAL. ADI 514/PI, julgada em 24/03/2008. Disponível em: http://www.stf.jus.br/portal/peticaoInicial/ verPeticaoInicial.asp? base $=\mathrm{ADIN} \& \mathrm{~s} 1=514 \&$ processo $=514$. Acesso em: 15. out. 2009.

. RE 248869/SP, julgado 07/08/2003. Disponível em: http://www. stf.jus.br/portal/jurisprudencia/listarJurisprudencia.asp?s1=248869\&base =baseAcordaos. Acesso em: 15. out. 2009.

. ADin 595/ES, julgada em 18/02/2002. Disponível em: http://

www.stf.jus.br/portal/peticaoInicial/verPeticaoInicial.asp?base=ADIN\&s $1=595$ \&processo=595. Acesso em: 15. out. 2009.

VIDAL, Jânio Nunes. Elementos da teoria constitucional contemporânea. Salvador: Jus Podivm, 2004.

Enviado em: 08/2009

Aprovado em: 10/2009 